\title{
Participatory IT in Semi-Public Spaces
}

\author{
Susanne Bødker $^{1} \quad$ Clemens Nylandsted Klokmose $^{1} \quad$ Matthias Korn $^{2,1}$ Anna Maria Polli ${ }^{1}$ \\ bodker@cs.au.dk_clemens@cs.au.dk \\ ${ }^{1}$ Center for Participatory IT and \\ Department of Computer Science \\ Aarhus University, Denmark \\ ${ }^{2}$ School of Informatics and Computing \\ Indiana University, IUPUI, USA
}

\begin{abstract}
This paper reports on an in-the-wild design experiment aiming to support participation and engagement in the semipublic space of a temporary art exhibition. Through interviews with 19 visitors we analyze the collaborative production of text about artworks in the exhibition in the physical space of the gallery. Our design, deployed throughout the venue for one month, makes use of people's personal mobile phones to interact with shared digital displays in the gallery. The findings help us understand and develop the notion of local participatory IT from actual use. We discuss people's diverging perceptions of what one is participating in and why as well as the impact of previous experiences with mobile technology. This leads us to propose three strong concepts to support understanding and design of technologies that foster local participation: Local area networking, hyperlocality, and global read/local write.
\end{abstract}

\section{Author Keywords}

Participation, locality, semi-public space, art exhibition.

\section{ACM Classification Keywords}

H.5.m. Information interfaces and presentation (e.g., HCI).

\section{INTRODUCTION}

With 'Web 2.0' and online social technologies, the scope of user participation and collaboration has broadened from work settings to technologies that can be redesigned, appropriated, molded, and shared by everybody in their everyday life. Wikipedia, for example, has demonstrated how knowledge production can be made more participatory, and has hence challenged traditional power relations between sender and receiver and the curation of knowledge. In our research, we are interested in how similar mechanisms for technology-supported open participation fostering debate, deliberative decision making, or collaborative knowledge production can be linked to a particular locality within shared and public settings: The physical space of an art exhibition, a public library, or a community center. Our aim is to make open participation possible at scale, i.e., throughout and better integrated with people's everyday life and the spaces they inhabit. Hence, as a first step, we are exploring participatory information technology that is local to a particular space, physically embedded in a shared and public setting - in contrast to designing a globally accessible service without attachment to a particular locality.

In this paper we explore this notion of local participatory IT through an in-the-wild design experiment on how participation may happen in the semi-public space of an art exhibition, where participants come and go and may only visit the exhibition once. Semi-public spaces are spaces that are owned and controlled by a private entity or institution, but open for the public (e.g., a café, a train, a movie theatre). Often, one would have to pay or consume to enter, or the activities tolerated may be restricted to relate to the space's particular purpose. Hence, introducing participatory IT in such spaces inherently involves a degree of relinquishment of power from the public to the institution, and vice versa.

We report on the design and deployment of Local Area Artworks (LAA). In LAA, conventional curatorial descriptions of artworks are replaced by texts on digital panels collaboratively written and re-written by visitors during the exhibition, using their personal mobile devices as mediators. The system detects when visitors are in close proximity of an artwork and redirects their browsers to the respective editable text. With LAA a part of the usual curatorial activity of authoring interpretive descriptions for artworks is opened up for participation by visitors, artists, curators, staff, etc.-effectively anyone physically present in the exhibition space. They participate through their collaborative interpretation of artworks. Hence, with LAA we are making the existing interpretative role of the audience explicit and visible by enabling co-interpretation among audience members in the physical space (cf. [25]).

IT to support participation and engagement in museums and exhibitions has received much attention. Macdonald [20] gives an excellent overview of art institutions, the curatorial process, and the deployment of IT in museums in general. Social media is increasingly used to involve audiences under the notion of the participatory museum (e.g., [9]). Phillips [22] discusses the idea that a Wikipedia-like technology 

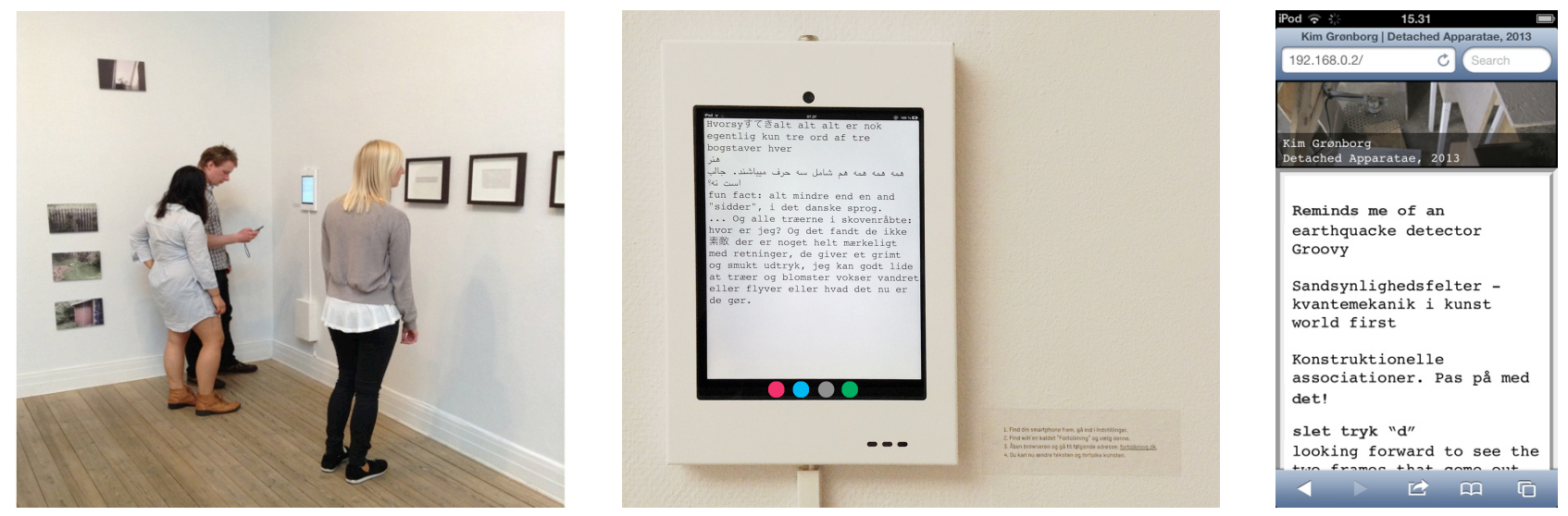

Figure 1. LEFT: Visitors interact with the panels through their personal devices. (A video figure accompanies this paper.) CENTER: A digital panel with instructions on how to connect next to it (i.e., open settings, connect to WiFi 'Interpretation', open a browser and go to 'interpretation.dk', edit text). RIGHT: A smartphone connected to a panel with the text for visitors to edit.

may move curation toward more openness and democracy. Moreover, there is a large body of work in HCI on visiting experiences more generally (e.g., [6,7,26]). While our setting is a temporary art exhibition, our particular interest lies in participation and locality more broadly.

To explore these aspects, LAA encompasses a number of design hypotheses regarding how we could engage visitors: E.g., by enabling the use of personal devices, by creating a low barrier for participation through a zero-install approach, and by using proximity detection to create a strong coupling between the act of writing and the object of the writings while also easing navigation within the system. We will discuss how these design hypotheses were met in the wild.

In order to understand how we may explore the novel practice of collaborative interpretations of artworks through a novel technology deployed in the gallery space, we turn to Grudin [12]: A central characteristic of our setting is that engagement and participation are ephemeral and in-themaking. The exhibition is not permanent but a temporary one of local artists only on view for a limited period of time (one month). Many visitors may only view the exhibition once. The technology is new and its collaborative use in the gallery only just beginning to take shape. Such new forms of social encounters mediated by new technologies are 'first of its kind' and 'in the making' [12]. Hence, Bødker and Christiansen [2] suggest to be concerned with the actual emergence of practices beyond exploring existing ones in order to study ephemeral settings and to design for them.

Our general approach is the following: Through the experiences and insights from the design experiment and interviews with 19 visitors of the exhibition, we discuss people's diverging perceptions of what one is participating in and why as well as the impact of previous experiences with mobile technology. This leads us to propose three strong concepts (i.e., intermediate-level design knowledge constructs residing between particular instances and generalized theories [15]) to support understanding and design of technolo- gies that support local participation: Local area networking, hyperlocality, and global read/local write.

\section{DESIGN PROCESS AND EMERGING DESIGN FOCUS}

The setting for our design experiment was Kunsthal Aarhus, a venue for contemporary art in Denmark. Together with management and staff at this art gallery we identified what seemed to be a suitable event, an exhibition by a local art collective called Guirlanden scheduled for the extension of May 2013. The exhibition went under the title New G. It was a traditional art exhibition in three rooms with a mix of paintings, sculptures, and installations.

Kunsthal Aarhus and Guirlanden allowed us to experiment with making the writing of description panels in the exhibition a participatory activity - an activity otherwise in the hands of the curator. Such a description panel with up to one page of text may accompany some artworks in addition to factual information provided (e.g., artist, title, year). It may describe the artist, the art piece, and its relation to the exhibition as seen through the professional eyes of the curator. The idea was to allow the audience to participate in producing joint curatorial texts through the use of their personal mobile devices. Hence, physical description panels were replaced with digital displays containing the text that could be edited by visitors using their smartphones. Six of the 14 exhibiting artists volunteered to have a digital display installed next to their artworks (see Figure 1 left).

As we went into the field, we already had a specific agenda of a series of design ideas relating to participation and locality that we wanted to explore (see following section). To negotiate the diverging agendas at play, the design process included a number of meetings, workshops, and ad-hoc communications with staff and artists. We had in total three formal meetings with the artists and their curator as well as four separate preparation meetings with the staff of the art gallery. Staff and artists were integral in shaping how our ideas evolved, were applied, and integrated into the exhibition. The meetings served, e.g., to align the set-up with the practical constraints and aesthetic requirements of the insti- 
tution and artists as well as with the overall visiting experience. Additionally, researchers with backgrounds in art institutions, art history, and interaction design in museums were involved in the project, and hence in shaping the design experiment for the concrete setting.

We anticipated that encouraging the use of mobile phones in an art exhibition would possibly create tensions [14,23]. However, since visitors already used their phones in the exhibition space (e.g., to take pictures or to text), we decided to make use of them and employ them for something relating to the artworks.

\section{Design rationale and hypotheses}

In our early dialogue with artists and the staff of the venue, an idea was formed about Wikipedia-inspired collaborative authoring in and about a local space. Wikipedia is an excellent example of a technology that supports the collaborative production of text across a community of quite different contributors $[4,16]$. We were interested in exploring whether a similar type of collaborative authoring could be achieved in a local physical space like an art exhibition. There is a wide body of work related to the use of Wikipedia-like technologies in museums and art galleries (e.g., [22]). Much of this work has a strong focus on the permanence of the curatorial texts, the engagement itself, and the relationships between contributors. We, in contrast, take the gallery as an exemplary setting for the fleeting and more ephemeral kind of engagement in (semi-)public spaces.

With the staff of the art venue we shared an interest in anchoring a digital layer to the local space. This anchoring we sought to explore through LAA, i.e., by coupling collaboratively produced digital text to particular artworks. A core idea was to use people's personal devices as a means for participation. The hypothesis was that the use of personal devices would create a sense of familiarity, of being on home turf, and allude to visitors' existing skills and experiences with their devices. Making use of personal devices can require significant bootstrapping on the side of the user in the form of downloading and installing apps. We sought to foster initial engagement through a more seamless approach requiring zero installation on the user's device. Zero install creates a very low entry barrier for participation and leaves personal devices largely untouched.

We were further inspired by how public WiFi hotspots often create interesting socio-spatial dynamics around them [13], and how a captive portal technique is frequently employed in such hotspots (e.g., as a pay wall, for commercials, or to have users agree to the terms of use). Technically speaking, when one connects to such hotspots, one does not connect to the Internet directly, but first and foremost to a local network that happens to provide Internet access as well (WLAN: wireless local area network). We hypothesized that bringing the original notion of connecting to a local network back to the fore would allow us to spur various digital participation activities in physical space $[10,19]$.
We further hypothesized that contributions about local matters flourish best when people write about what they immediately see and experience. Physical proximity creates a natural and strong coupling between the written text and the object of interest [1,11]. This lead us to require physical proximity of the user to an artwork in order to allow editing its associated text thereby strengthening the coupling between physical and digital layer. Hence, for this reason and to minimize the amount of navigation required on the users' behalf, we wanted to make navigating between different artworks in the exhibition as automagic as possible by basing it on the user's location in the gallery. The digital panels next to each artwork give the digital activity a physical representation in the space.

To encourage collaborative editing we hypothesized that a metaphor of a single page of text would force people to take into account what others have written and to edit (and potentially delete) what is already there. The single page of text limited the amount of text per artwork and allowed us to display the text on fixed displays in the exhibition space. While text should only be written at the artworks, we hypothesized that providing read access to the texts through the institution's website would help to sustain participation.

\section{The design}

The resulting design consisted of six digital panels mounted next to six individual artworks throughout the exhibition. The panels mediated collocated same-time and differenttime collaboration [24], where users could edit text and write new text, within the one-page format while standing in front of the specific art piece and display. To emphasize the collocated use, text was live-updated on the digital panels and other connected devices as people would edit the texts on their personal phones. This live editing was realized through a web-based collaborative editing engine. Dots at the bottom of the panels showed how many people were connected and actively editing at the moment (see Figure 1 center). The newly written text would appear in the same respective author colors across all devices and the panels to create awareness of the same-time editing of several people. Text was limited to the visible area of the one-page display, and no scrolling was enabled on the panel. When the display was full, users got a notification on their phone to delete or edit what had previously been written.

Visitors connected their own smartphone (or a borrowed device) to a dedicated open wireless network that, beyond our system, provided no Internet connection. When visitors opened a browser on their phone, they were automatically redirected to our web-based system. Making use of WiFi proximity detection [17], the browser would be redirected to an editable version of the text for a particular panel when they moved into its proximity (within 2 to 3 meters; see Figure 1 right). Moving to another artwork automatically redirected to the respective editable text. Moving out of proximity of any panel, users were presented with an overview of the art gallery indicating the locations of the panels. 
Members of the audience could only participate actively by being there, by being in close physical proximity of an artwork. Once they moved out of proximity of the art piece, they were no longer able to edit text.

To realize 'zero install', everything was based on webtechnology and accessible from any (relatively modern) smartphone browser. The overall setup offered minimal descriptions and instructions. A small label next to the panels provided connection instructions (Figure 1 center). The texts were only editable at the venue, but one could follow all activity from afar through the Kunsthal's website.

The panels were styled and framed to match the aesthetics of the venue, to blend in and look ordinary. They were not interactive in themselves but only displayed the collaboratively written text relating to the given artwork. At the start of the exhibition, the panels were deliberately left blank in order not to suggest particular kinds of writings or usages to the audience. Neither we, nor the curators provided any initial texts or interpretations about the artworks.

\section{RESEARCH METHODOLOGY}

The ephemerality of use and the emerging practices in the setting $[2,12]$ call for exploratory design processes that go beyond exploring existing practices, and accordingly technological prototypes were seen as our way of probing these emerging forms of participation. The setup as such was time-limited, leading us to carry out a time-limited in-thewild study [5], where we studied what the audience actually did with the technology, and how what they did could be seen as the start of new participatory practices.

To understand use in the wild, we conducted 13 semistructured on-site interviews with 19 visitors (some in pairs) ranging between 20 and 45 minutes. ${ }^{1}$ Interviews focused on visitors' experiences regarding the exhibition and their use or non-use of the digital panels. We also conducted observations on four days, two hours each. Lastly, we recorded the full history of the text being written. A variety of people took part in the studies, such as families, couples, and individuals, among those were regular visitors and artists. The interviewees' ages ranged from around 15 to 65 . They were interviewed individually and in pairs (see Table 1).

This paper specifically addresses the interview data, in parts because the observational data were difficult to use for getting in-depth about users' experiences given that interactions were brief and sporadic. The interviews were transcribed and then analyzed using inductive coding. Initial codes related to our design ideas such as participation, reading/writing/deleting, proximity (near/far), mobile/panel/art-

\footnotetext{
${ }^{1}$ The same raw interview material has been analyzed under the perspective of the development of human practices between initial familiarity and future use possibilities based on socio-cultural theories of artifact-mediated learning and collaboration (see [3]).
}

work, etc. In ordering and reading through the interviews based on these codes we realized that often what looked

\#1: $\quad \mathrm{N} \& \mathrm{D}$, a couple (woman and man) in their $20 \mathrm{~s}$.

\#2: Woman in her mid 60s, visiting alone.

\#3: Man in his early 40s, visiting alone.

\#4: D \& L, a couple (woman and man) in their end-20s.

\#5: Woman, teenager, visiting with her parents.

\#6: $\quad$ Man in his end 30s, visiting alone.

\#7: A \& P, father (late 50s) and daughter (early 20s).

\#8: $\quad K \&$ E, a couple (woman and man) in their early 30 s.

\#9: Man in his mid 50s, visiting with his family.

\#10: V \& M, siblings (woman and man) in their mid 20s.

\#11: Man in his early 50s, visiting with a friend.

\#12: M \& C, a couple (woman and man) in their mid 30s.

\#13: Woman in her early 30 s, visiting alone.

Table 1. List of interviews and interviewees.

interesting was the contradictions, e.g., in how people talked about the phone in the art gallery, or what it meant to be close to an art piece. Accordingly, in subsequent rounds of analysis we looked in greater detail at the alignment and conflicts between the assumptions made in the design and use as it unfolds and is talked about in our interviews.

\section{FINDINGS AND ANALYSIS}

In the following we present findings from the interviews grouped under four headings. These findings are in line with results from an informal analysis of our observations.

\section{The familiarity of personal devices in art institutions}

The idea of connecting to the panels in the room through their phone may not be very familiar to people even though they normally carry smartphones. So how did the interviewees talk about this familiarity and the use of smartphones in the art exhibition at large? In studying the interviews we have identified a tension with visitors increasingly using their personal devices in art exhibitions.

This tension presents itself in two somewhat opposing reactions. The first reaction is the often-iterated distraction mobile phones present in many social settings. It was seen as socially inappropriate ("am I bored?") and going against norms and expectations in such kinds of settings ("normally you don't do that"): "it's a bit strange to take out your smartphone actually, because normally you don't do that when you walk in an exhibition. It feels a little bit like: now I take out my phone, am I bored? (laughing)" (interview \#1, respondent $N: \# 1 N$ ). It was further perceived to be personally distracting from the individual artworks, the experience of the exhibition as a whole, and other people one is with: "I don't think I like walking around with my phone when I look at the exhibitions so I mostly leave it somewhere in the wardrobe, because to me it is kind of like an element that distracts me" (\#10M). Hence, the users' orientation toward the artifact (the mobile phone) on a motivational level in fact inhibits use. In this respect, it may be asked if the mobile phone is an all too familiar gateway, an all too mundane and everyday personal object that may take away a 
little bit of the excitement and peculiarity of visiting an art exhibition?

Taking out your phone may further display that one is not really fully present in the space but perhaps immersed in conversations with others afar, e.g., texting or being on Facebook, most likely doing stuff unrelated to the exhibition and the artworks. The use of the mobile phone (and the setup at large) was perceived as taking away face-time with the person(s) one is there with at the exhibition-as illustrated through the following interview snippet:

"respondent: [..] it is kind of like having a discussion with somebody who is not there, but then you can also maybe think, maybe I should have been having this discussion with [my partner], who is there, instead of looking at my phone. And I think, that's a negative thing; that I am kind of looking at the phone, instead of being present in...

interviewer: But you mean you should have a discussion with [your partner],

respondent: yes

interviewer: and you think by writing on these panels, it kind of limits the discussion that you would normally have with [your partner]?

respondent: mhhh, I am not sure, because I don't know exactly how we would have gone about this if we hadn't had it, but I know that I am concentrating on something that's just for me. I am not experiencing the room in the same way, if I have to ... and that would be different than as if I was writing [directly] on the wall. Then I would be more in the room, I think." (\#12M)

This shows that talking to your friends and partners was perceived as being more worthwhile than using the phone to interact with strangers that are not currently present in the situation. The set-up did not facilitate interactions with co-present people and may even suppress or hinder them.

The second reaction, however, which goes very much in line with our design hypothesis, is that the use of personal devices creates a sense of familiarity: "it is like an everyday device. You recognize it and you are not afraid of using it. If it is something special then maybe people have some kind of distance to it. But now it is just like an everyday thing," (\#1D). Interviewees specifically highlighted their familiarity toward typing small comments or messages on their devices, a practice they are rather used to (e.g., texting, tweeting, status updates, etc.): "it is much more natural to write with my own phone, it definitely helps [..] like being used to write SMS with your phone [..] So that's very nice, that helps" (\#12C). Several interviewees remarked that using one's smartphone for text entry "felt natural:" "yeah, it felt ok. It was easy to get it done. It felt natural. [..] It was just typing a text or something. So it isn't that hard. It was easy to get connected" (\#1D). They partly ascribed this to their familiarity of actual text entry as these quotes illustrate, and partly to the hassle-free nature of connecting to, of participating in the system due to zero install and automagic navi- gation (as per our design hypotheses): "after I logged on to my phone, it worked good, I just texted on my smartphone and it came on to the iPad" (\#6) or "it is fun to be able to come and do things with your phone directly" (\#12C). Hence, users explicitly activate their experiences with use and handling of their phone from other activities.

The interviews further point toward a tendency where the panels, by way of being present in the space, entice conversations and discussions that may not normally take place. They prompted visitors to verbalize their thoughts that they would not necessarily verbalize otherwise (be they actually typed into and represented on the panels or just exchanged offline). The system made people think and reflect about the artworks: "I think it, well, it forces you to [form] an opinion about the artworks. Normally when you look at art, you can just say I like it or don't like it, and then [you go to the] next [artwork]. Here, you need to put words on your feelings and what the artworks do for you. I think that's a good thing because a lot of time when you look at art, it's just like browsing through a catalog. [..] And here you are forced to take a stand" (\#4L).

In sum, we have identified tensions within the ongoing negotiations of visitors increasingly using their smartphones in art exhibitions. There are a number of partly social conventions that break, affecting people: The signal of getting bored, the focus away from the people you are with, and the concern that the smartphone as such distracts the exhibition experience and potentially the magic of being drawn into the art. At the same time, however, our participants react to the utilization of mobile devices by pointing toward their familiarity with them. Hence, it seems the handling of the smartphones to produce text is well-trained and smooth.

\section{Participation in exhibition interpretation}

One intention with the design experiment has been to challenge curatorial processes through introducing means of visitor participation in the interpretive communication of artworks. The interviews demonstrate that this creates an interesting tension shaking up the existing configuration of the artifact ecologies in art exhibitions (with artworks and static descriptions) through introducing the panels and people's personal mobile phones into the gallery space. In particular, the resulting atmosphere change in museums has been addressed: "I think it's nice that you kind of change the thing that normally when you go to museums, it's all about being quiet and just standing and listening. And suddenly, without interrupting the quietness, the silence, you get to communicate with the other people around" (\#7A).

The presence of the set-up was a source of confusion for the interviewees. What is it about? What does it show? Who is it from? Who is it for? Initial perceptions often alluded to conventional understandings of art exhibitions and the curatorial process, where interviewees tried to align the new artifacts with previous experiences and expectations. For example, the panels were initially perceived as providing 
static information about the art pieces perhaps from the curator or the artist itself: "I didn't understand exactly what it was. I thought it was... because in summer I read some explanation about the art. Because everyone has written that. So maybe I thought it's just like information about the art. [..] But then I saw like some other comments and started to think what is it? (laughing)" (\#1N).

In the same vein, interviewees were confused about the sender of these statements (in general, but also in particular because contributions were anonymous): "It took me some time to figure out that this was something that other people wrote, and it wasn't something that the artist wrote" (\#12M). And they were confused who was the receiver; who were you writing to and for: "I used it for... I don't know... (laughing) to write my opinion, to write my opinion and maybe I was thinking I was writing to the artist" (\#6). The same interviewee, in figuring out the system, was even initially tagging his name while most other comments were left anonymously: "On the first one I wrote my name, on the others I didn't (laughing) [..] I felt like I was telling, if it was good or bad art, but then I wasn't that much of an expert" (\#6). Our intervention seemed to challenge and confuse these relationships.

Interviewees across the board appreciated the opportunity to read what other visitors thought about the artworks instead of such texts coming from the curator: "I thought it could be really interesting if people wrote like, yes, their point of view on what they liked about the piece of art, or didn't like" (\#1N). Plus, they enjoyed being pushed to think and even write about their feelings about artworks. One interviewee directly addressed that this way of "activating the audience" could supplement or even substitute curatorial statements: "I thought about activating the audience instead of just letting the curator create the direction and write something. So normally the audience has to look, listen or experience the art and then read some text. [..] It really much depends on these texts, because they can be good or bad" (\#4D). Others suggested that this way of involving the visitors, made the art less "elitist" but rather more inclusive: "I think it's a good way to keep the art from being elitist, because sometimes art, paintings, dance and music can be kind of elitist, and it's few people that have the right answer. In this way everybody has an answer, and everybody has an opinion on it, and there is no wrong opinion" (\#4L). The intervention opened the power to define the interpretations of the artworks from the expert curator to the general audience. According to the interviews, it allowed for more varied and diverse feelings and opinions in interesting ways, because everyone saw something else in the artworks. They evoke different feelings in different people.

However, some respondents also felt challenged (positively and negatively) to write something smart (enough), something that might even intrigue others: "suddenly you had to feel like you really had something important to say or you just shouldn't"' (\#7A).
Summarizing, the intervention is seen to provide a forum where visitors connect with one another; where the exchange of views and feelings is in the center. The interviews suggest that people consider both the art and the panels as part of the artifact ecology of the art exhibit. They are familiar with the concept of curated texts accompanying art pieces, and many see a wish for more democratic engagement among visitors in shaping these. However, there is a lot of ambiguity in how they see what they participate in.

\section{Perceptions of the panels and their text}

The panels to a large extent take their format from a typical curator's note, which most often did not exceed one page of text in A4 format; sometimes they are even shorter. Another inspiration has come from Wikipedia where, while the text may be longer, it is also one coherent piece of text despite potentially many contributions. Looking at our interviews it is however quite obvious that these two sources of inspiration are not thoroughly conveyed to visitors through the design and set-up. The question that we may ask the data, then, is how do visitors perceive the text? And how do these ways of seeing the text clash with the original design ideas?

One interviewee compared the set-up to a whiteboard: "This really looked like a whiteboard, right? This was a whiteboard, where you write and when there is no more space you delete, and then you write up again, and then delete, and there is no history" (\#12C). The interviewee remarked the anonymity and even the inability to distinguish between individual snippets from different authors. He also remarked the absence of any given structure (e.g., threaded discussions): "I thought that the fact that there is only one white box with text, and it is a bit confusing, it is not very clear to see who wrote what and it is like hard to have a discussion" (\#12C). In the interviewee's further explanations the metaphor brings with it a sense of instability (text can be deleted or even completely wiped at any point in time) and a lack of permanence (there is no visible history): "in the middle of writing next to something, you know it can go away after a second and it doesn't feel permanent and it's not attached to you in any way" (\#12C). With the last bit, this interviewee reflects a repeating theme where visitors did not really feel they were offering something of value that could be called a 'contribution', but rather a random thought from the top of their head.

Another comparison that came up, specifically when looking at what was actually written on the panels, is the idea of a guestbook where one writes short greetings: "I think it depends a lot on what people write, actually. Because if people just use it like a guestbook, just to write 'Hi Hi, I'm here. I use this.' Then, probably, you won't get so much out of it [..]. But I think the real advantage comes from people actually [being] more focused on what they think about this piece of art, because that's what's interesting for other people to read and that's what's interesting to discuss more specific about each art piece" (\#1N). It was remarked that other visitors only left short and at times unrelated messag- 
es, in the same vein as one would on Facebook and when texting, where instead interviewees wished for more topical comments and discussions about the artwork itself.

A further tension revolves around the nature of the produced text. On the one hand, our design hypothesis was concerned with one coherent piece of text, perhaps a collaborative interpretation of the artwork. Interviewees on the other hand saw the outcomes as unrelated messages or, at best, discussions among visitors (and perhaps with the artist). They tended to want to make sense of the text in the format of a discussion, not a collaborative text. They sought for the individual comments to be knitted together in a better way and to be referring to each other (e.g., answering to the previous comment or creating a string of associations across comments): "maybe it would be nice to actually make it a discussion, this is just like random comments" (\#12M). This diverges starkly from our assumptions of use.

Visitors did not consider editing (or even deleting) other's comments, because they were not 'their' comments. Even if they would like to edit text, they were shy of touching other's contributions: "but it would have been fun to just correct text made by the others, but I didn't. I guess I'm too polite to do that" (\#6). They were hesitant partly because they did not feel they would come up with anything better than was already there, coupled with the lack of a visible history through which people would know that everything is backed up (i.e., a feeling of a lack of permanence): "because what I was thinking is: Do they keep a record of all that's on the screen? Because if I knew that beforehand, then I would just delete stuff, and write [something] new" (\#4L) and "just write 'Please delete and edit the other comments. We got it all backed up.' Something like that. Because we were afraid that we would delete something that was actually good in order to [make] our own point. And that wasn't appealing” (\#4L).

When visitors were forced to delete text in order to write something of their own, discussions ensued weighing which comments were of least value: "One time you had to delete something else, because there was not enough room. Which was quite funny because we had to have a discussion, which sentence to delete to put ours in there" (\#7A). Or, people refrain from writing altogether because of reservations to delete other's comments: "I wanted to write something, and I couldn't, if I didn't delete anything. But I thought it was a little bit weird, because how do I choose what to delete that somebody else wrote. So I chose something that was maybe, I don't know, that I didn't think was very inspiring. (laughing)" (\#12M) and "[I felt] a little bit guilty, because I think every person has their own feelings or suggestions, or something that they want to express for this paintings. If I delete them, it is actually kind of impolite to delete their feelings" (\#13). In sum, they did not see a responsibility or a drive in shaping the joint text, but rather perceived it as a mix of distinctive comments from different people in a larger conversation where everyone is only ever touching his own small snippet even if more is possible.

In total, there are many sources of inspiration for the actual use of the set-up; be they texting, messaging, discussions, Facebook posts, a guestbook, or a whiteboard. These do not all live smoothly alongside one another. And all are to varying degree markedly different from the one-sheet joint interpretation text that we as designers imagined. Not only are we designing for emerging practices, the character of the texts as such is also changing throughout the study.

Voices in the exhibition: Who is talking and from where? Our design hypotheses emphasized the idea that the text is readable from everywhere through the Internet, but that people need to visit the venue in order to discuss the artworks. Accordingly, our material shows a tension that reflects this difference between local and global: between a website (i.e., global access) and that of writing locally. In addition physical proximity plays a role, how close you want and need to be, and whether exploration by the audience belongs directly at the art piece or elsewhere.

Interviewees perceived a number of diverging relationships between the panels and texts and the artworks, often in relation to how they were physically placed. Some indicate that because the texts are interactive, they blur the boundaries and make visitors think that they are part of the art; or that the artist should at least choose to have it: "when I saw the first work in there with an iPad, I thought it was just part of that work. So it was, I thought, the artist tries to make the audience interact. But then I saw it was at most of the works. Then I realized it was... I don't know" (\#6) and "I think, maybe to me it kind of means a lot that while you stand next to the work of art that you can read about it. So I think that the artist has [to choose to have it.] I think it has to be a part of the work of art" (\#10V).

There were other views that remarked that the panels add something to the art-extend it-provide another layer: The idea of writing on the panels was understood as "to [...] prolong the artwork, to expanded it, to add some interpretations. [...] So I thought maybe it's all very open art" (\#6) and "[\#1D:] if you could delete something then it will become like a piece of art in itself, because... [\#1N:] yeah, because it becomes interactive and reflection about the art, it becomes like a layer to the art [...] [\#1D:] because, yeah, it creates something new at that point."

In terms of proximity and the coupling of location to art pieces, the quotes demonstrate a bit of confusion. One respondent specifically remarked how the set-up forces you to behave in a certain way in the exhibition, not the least relating to your physical movement through it: "at some point I got a little impatient because I was like 'ok, now I actually am finished with the artwork and I want to go to the next one, but no I have to stay, putting in these words.' And [my father] is already gone a couple of minutes and you just want to get finished. And it was a little hard for me to get 
the buttons right and stuff like that. [..] You're kind of forced, forcing yourself to stay somewhere even though you feel that your feet are moving” (\#7A). The set-up not only guided you through the exhibition if you were so inclined or so disinclined to follow the panels, to look for the next panel rather than the next artwork (not all artworks were fitted with panels); it also forced you to remain in the arbitrarily defined proximity of an artwork if you want to contribute to it, to write something. If you moved away from it you would also be redirected away from the editing capability on your device. You would be interrupted in your writing.

In terms of remote access, one interviewee argued that all of the contributing could just as well happen from home so as to be able to think about it first: "You kind of want to like see what the other ones have written, and maybe go home and write about what you saw. I don't think all of it has to happen right here... Also when you have left this place and thought about it what you have seen" (\#10V).

In sum, users were split between seeing the panels as separate or integrated part of the artwork; hence, of identifying whether they were participating in art or art interpretation. In addition, the proximity created interesting tensions in experiencing the exhibition.

\section{Summing up}

Challenging some of the traditional curatorial practices in an art gallery in a participatory manner led to surprising metaphors for what people actually were participating in. Some expressed that they were participating in the artistic expression of the artworks, while others participated through a stream of commentaries. The use of phones had familiar yet scary features that challenged the here-and-now togetherness of people in the exhibition space. The panels shifted the relationship between the art pieces, the curation, and the discussions of the audience. In terms of participation, the panels seemed to shift involvement, engagement, commitment, and group action from happening among a group of visitors toward an engagement that is on the one hand for people individually (drawing attention away from the group), and on the other hand opening for involvement and commitment toward other groups-either other visitors over time or groups of artists, curators, and staff. Accordingly, it seems that, in terms of participating in a joint endeavor, who people were together with and what they were together for shifted through the introduction of LAA into the semi-public space of the gallery.

\section{STRONG CONCEPTS FOR LOCAL PARTICIPATORY IT}

LAA is one of our seminal experiments with what we refer to as participatory information technology in semi-public spaces. It is also a design exemplar within this new (and still underexplored) design space. In the following, we formulate three strong concepts that, in retrospect, had significant importance for LAA. These strong concepts draw from our experiences in designing and deploying LAA as well as our insights from the interviews analyzing users' percep- tions and emerging use practices. We believe the concepts are potentially interesting avenues for further investigation into IT support for local participation in semi-public spaces.

Höök and Löwgren [15] describe strong concepts as an intermediate-level of knowledge between specific instances and general theories that interaction design research can draw attention to. This intermediate-level knowledge specifically includes generative strong concepts that are partial ideas with elements of potential design solutions that can be appropriated by designers and researchers. At the same time, they can be used for the creation of new design instances. These strong concepts concern the dynamic gestalt, i.e., interactive behavior rather than static appearance. Moreover, these strong concepts reside in the technological artifacts while also speaking of practices of use.

\section{Local area networking}

This concept relates to interviewees' experiences with the set-up embedded in the space of the gallery. We worked with the idea that visitors would not have to install something on their devices to participate. Instead of some application on their smartphones, we considered the existing network infrastructure of the space to be the application platform through which visitors could engage with the space and other people in it by way of their personal devices as mere interfaces. Inspired by the term for the technical infrastructure we call this 'local area networking'.

In our implementation of the concept, building on top of the already existing local network meant two things: First, it meant that we were building web-based interfaces which users could access through the browser on their phone. Consequently, our approach required zero installation of any software components on user devices, and thus provided a low (technical) entry barrier for the ephemeral/one-off participation of gallery visitors. When they connected to the dedicated network, visitors were literally drawn into the participation opportunity by a catch-all HTTP redirect to our system. When visitors left the space again nothing remained on their devices; we did not litter their devices with software largely irrelevant and uninteresting to them outside the confines of the space.

Second, the concept of local area networking meant that we needed to bridge digital and physical spaces, that is, to extend the digital and in the space invisible network activity into the physical space of the gallery. For LAA, we designed the digital description panels to be physical representations of the activity going on at each artwork (i.e., the collaborative text production). The panels bring the otherwise invisible activity into the socio-physical space of the gallery-i.e., for each and everyone to see, including nonusers merely browsing the exhibition without a phone.

Seeing the characteristics of the space being central, the art institution, in our case, imposed its own norms, values, and conventions. As we saw, some considered bringing the cellphone into the exhibition a matter of concern. Others ex- 
pressed discouragement because they could not figure out something clever enough to write. With local area networking, we draw attention to a form of participation and engagement that is more closely tied to the socio-physical space rather than to individual users. At the same time, our implementation maintains the advantages of people's familiarity with their devices, a feeling of being on home turf, due to the use of personal phones.

In sum, using local area networking as a design concept means creating a digital layer that is tied to the physical space through fixed and/or mobile devices present in the space.

\section{Hyperlocality}

This concept relates to interviewees' experiences with the required proximity to artworks. In our set-up visitors engaged with the panels and the artworks that were aligned with each other not only in a local physical space, but where, in order to participate in writing, visitors had to come close. We adopt the notion of 'hyperlocality' from journalism to describe this strong concept.

Hyperlocality concerns to be immediately confronted with a physically located issue at hand-be that an artwork, a future building site, or an event in the neighborhood. Our hypothesis has been that it is beneficial to immediately experience the issue in its context at least initially when engaging with it.

To support (and even enforce) this technically we build on proxemic interaction $[1,11]$ by employing a technique for proximity-based editing [17]. Visitors could only edit the text of the artwork they stood immediately in front of. LAA 'automagically' navigated them to the corresponding text on their phone for personal as well as collaborative interaction (cf. [11]). As we saw, LAA also redirected them away again from the editing capability when they left. Hence, visitors were browsing the discussions with their feet.

The immediate presence of the panels with text and the mere possibility of writing something enticed reflections on the artworks and made people want to write something. At the same time, they felt pressured by other visitors standing next to them, following every little stupid thought or typo on the panel in real-time because of the lack of a reviewbefore-you-send functionality. On a related note, some interviewees expressed concern that they loose connection to their co-present acquaintances (cf. [8]). Use of personal devices, in part, lead to 'individual' participation. In our current design, we do not directly support engagement with those who are together.

Hence, with hyperlocality as a design concept we steer attention toward designing for participation and collaboration that centers on shared, collocated objects taking into account the immediate social environment in addition to the physical one. Not only your presence in the space, but also your position and orientation toward other people, objects of interest, and participatory means become relevant.

\section{Global read/local write}

This concept relates to interviewees' experiences with remote access via the gallery website. As much as we emphasize the local physical space and the immediate experience of engaging with it (at least initially), global access to the local activity is not irrelevant. The institution, but also members of the audience, and even non-visitors may have an interest in the activity reaching out beyond the local confines of the space. We addressed this with global read-only and local read/write access (cf. [21]).

Write access is exclusive to those present in the space (as explained thus far). Read-only access is intended for those who wish to follow up on the activity, e.g., from home-be that someone who has contributed locally earlier and wants to see how the comments develop, or someone who is just interested in what is going on. Potentially, some may even wish to re-engage based on what they have seen remotely. Allowing remote participants to merely read and follow what is going on in the space keeps power dynamics centered on the local level and the people physically present.

In LAA, no history or re-play of what was written was available neither to remote participants nor to people locally (although this feature was implemented). People, local or remote, could only see what currently was on the panels, in real-time. Thereby, LAA preserved the temporal rhythm and synchronicity of the activities. Everything took place there and then; and continued to be ephemeral.

The sustained participation that Wikipedia affords [4] did not occur with LAA. People did not seem to care enough about how their contributions were received and edited by others to follow up on them, in the exhibition or at home. However, we believe that this is by and large a result of the way the panels were appropriated as a vehicle for personal statements and not for collaborative text production.

In sum, using global read/local write as a design concept means extending beyond the local reach, but retaining the privilege of local physical presence.

\section{CONCLUSION AND FUTURE WORK}

We created a new technology to support emergent practices of participatory curatorial activity in an art exhibition; and through the study of its use explored a new design space for local participatory IT in semi-public spaces. We used the experiences from this design experiment to propose three strong concepts: Local area networking, hyperlocality, and global read/local write. These concepts are steps toward better understanding and designing support for participation in semi-public spaces, and hence toward participatory IT.

Local area networking and hyperlocality as design concepts emphasize questions pertaining to the privilege of being at a place physically versus accessing it online; whereas global 
read/local write access allow for the physical space to reach beyond its own confines. Stakeholders hosting participation opportunities in semi-public spaces may profit from bettermotivated and more-substantiated contributions due to people's immediate experiences with the issues at hand. Contributors as well as stakeholders may be interested in sustaining as well as in following up on situated contributions.

Furthermore, the ephemerality of the participatory practices studied, we suggest, is similar to and characteristic for (located) discussions in the civic arena $[18,19]$, where issues constantly emerge and fade away again as part of public discourse. This reinforces our wish to pursue the presented study as an opening to further studies in (semi-)public spaces and the civic domain, rather than as a new technology for museums and art exhibitions.

\section{ACKNOWLEDGEMENTS}

This work has been funded by the Center for Participatory IT at Aarhus University. We thank our partners in the project (Kunsthal Aarhus and Kunstnersammenslutning Guirlanden), our participants in the study, as well as Anne Vinsløv Andersen and Geoff Cox. We furthermore thank CAVI at Aarhus University for technical assistance.

\section{REFERENCES}

1. Ballendat, T., Marquardt, N., and Greenberg, S. Proxemic interaction: designing for a proximity and orientation-aware environment. Proc. ITS 2010, ACM Press (2010), 121-130.

2. Bødker, S. and Christiansen, E. Designing for ephemerality and prototypicality. Proc. DIS 2004, ACM Press (2004), 255-260.

3. Bødker, S. and Polli, A.M. Between initial familiarity and future use: A case of collocated collaborative writing. Proc. COOP 2014, Springer (2014), 137-154.

4. Bryant, S.L., Forte, A., and Bruckman, A. Becoming Wikipedian: transformation of participation in a collaborative online encyclopedia. Proc. Group 2005, ACM Press (2005), 1-10.

5. Crabtree, A., Chamberlain, A., Grinter, R.E., Jones, M., Rodden, T., and Rogers, Y. Introduction to the Special Issue of "The Turn to The Wild". TOCHI 20, 3 (2013), $13: 1-13: 4$

6. Dindler, C., Iversen, O.S., Smith, R., and Veerasawmy, R. Participatory design at the museum: inquiring into children's everyday engagement in cultural heritage. Proc. OZCHI 2010, ACM Press (2010), 72-79.

7. Ferris, K., Bannon, L., Ciolfi, L., Gallagher, P., Hall, T. and Lennon, M. Shaping experiences in the hunt museum: a design case study. Proc. DIS 2004, ACM Press (2004), 205-214.

8. Fischer, J.E., Reeves, S., Greenhalgh, C., and Benford, S. Designing Mobile Face-to-Face Group Interactions. Adjunct Proc. ECSCW 2013, DAIMI (2013), 104-111.
9. Giaccardi, E. (Ed.) Heritage and Social Media: Understanding heritage in a participatory culture. Routledge, New York, NY, USA, 2012.

10. Gordon, E., and de Souza e Silva, A. Net Locality: Why Location Matters in a Networked World. WileyBlackwell, Boston, MA, USA, 2011.

11. Greenberg, S., Marquardt, N., Ballendat, T., DiazMarino, R., and Wang, M. Proxemic interactions: the new ubicomp? interactions 18, 1 (Jan. 2011), 42-50.

12. Grudin, J. Group Dynamics and Ubiquitous Computing. Comm. ACM, 45, 12 (2002), 74-78.

13. Hampton, K.N. and Gupta, N. Community and social interaction in the wireless city: Wi-Fi use in public and semi-public spaces. New Media \& Society 10, 6 (2008), 831-850.

14. Heath, C., Vom Lehn, D., and Osborne, J. Interaction and interactives: collaboration and participation with computer-based exhibits. Public Understanding of Science, 14, 1 (2005), 91-101.

15.Höök, K. and Löwgren, J. Strong Concepts: Intermediate-level Knowledge in Interaction Design Research. TOCHI 19, 3 (2012), 23:1-23:18.

16. Kittur, A. and Kraut, R.E. Harnessing the wisdom of crowds in Wikipedia: quality through coordination. Proc. CSCW 2008, ACM Press (2008), 37-46.

17.Klokmose, C.N., Korn, M., and Blunck, H. WiFi proximity detection in mobile web applications. Proc. EICS 2014, ACM Press (2014), 123-128.

18. Korn, M. Situating Engagement: Ubiquitous Infrastructures for In-Situ Civic Engagement. Unpublished Ph.D. Dissertation, Aarhus University, Denmark, 2013.

19. Korn, M. and Klokmose, C.N. Putting 'local' back into public WiFi hotspots. Proc. UbiComp 2012, ACM Press (2012), 800-801.

20. Macdonald, S. Interconnecting: museum visiting and exhibition design. CoDesign 3, 1 (2007), 149-162.

21. Memarovic, N., Cheverst, K., Langheinrich, M., Elhart, I., and Alt, F. Tethered or free to roam: the design space of limiting content access on community displays. Proc. PerDis 2013, ACM Press (2013), 127-132.

22. Phillips, L.B. The Temple and the Bazaar: Wikipedia as a Platform for Open Authority in Museums. Curator Mus. J. 56, (2013), 219-235.

23. Reeves, S., Benford, S., O'Malley, C., and Fraser, M. Designing the spectator experience. Proc. CHI 2005, ACM Press (2005), 741-750.

24. Rodden, T. A survey of CSCW systems. Interacting with Computers 3, 3 (1991), 319-353.

25. Sengers, P. and Gaver, B. Staying open to interpretation: engaging multiple meanings in design and evaluation. Proc. DIS 2006, ACM Press (2006), 99-108. 
